\title{
Learning to Be a Tea Art Practitioner: An Anthropologist’s Self-Reflection*
}

\begin{abstract}
Shuenn-Der Yu
Institute of Ethnology, Academia Sinica, Taipei, Taiwan

Becoming a tea art practitioner, or charen (茶人), involves cultivation of body and mind. This paper attempts to document the long-term process of bodily and mindful cultivation from an anthropological, participant-observation, and self-reflective point of view. I will describe my experiences from entering the world of Taiwanese tea art through learning the great variety of teas and the techniques for making them, designing my own tea sets, and performing in tea gatherings. This learning process has gone well beyond what is required of a researcher, or a good observer, because it has not only allowed me to understand, interpret, and analyze the aesthetics and ritual of Taiwanese tea art but it has also required that I “designs” or be creative in presenting Taiwanese tea art to my own cultural members. This substantially changes my status from the objective observer my profession requires, to a dedicated performer and even a designer/creator of my own culture. My self-reflexivity in this process points to not only methodological issues but also theoretical ones, including recent academic interest in materiality, cultural performance, lifestyle, bodily discipline, and the senses. Through self-reflection, I intends to reveal connections among them.
\end{abstract}

Keywords: Taiwan, tea art, bodily cultivation, self-reflexivity, sense-scape

\section{Introduction}

Becoming a tea art practitioner (charen 茶人) involves the cultivation of both body and mind—a fact I have learned, or cannot but admit. It took me some time to realize this fact, not because there was a moment of enlightenment allowing me to recognize the essence of Taiwan's tea art, but because I realizes that I have internalized some of the elements of tea art's aesthetics into my habitus (Bourdieu, 1977), and they have become a part of my life without my conscious awareness. This paper relates how I discovered this process had taken place and how I has come to consider this finding, and the self-reflection that revealed it to me, crucial to our understanding of bodily cultivation and cultural learning.

\section{Entering Julu}

I became a tea art apprentice because I wanted to learn tea tasting. I had begun to seriously consider shifting my research focus from political economy to the body and senses, and I decided to study tea in a

\footnotetext{
* Marc Moscowitz kindly read and commented the first draft of this paper, to which I am deeply appreciated. Shuenn-Der Yu, research fellow, Institute of Ethnology, Academia Sinica.
} 
systematic manner so I could learn more about culture and bodily experiences in an unmediated way. A friend introduced me to Julu, a Taipei-based tea club famous for its aesthetics and tea ritual performances, in the spring of 2009. I was invited for an interview.

When I met Master Lee, I briefly explained my intention to learn tea and especially tasting, to enhance my study of Taiwan's tea culture. To my surprise, the master told me she did not have a well-organized program. She explained that many new students asked about course materials when entering Julu, but it was not her style to run a structured course of study. She went on to share with me her idea of what it meant to be a charen or tea-art practitioner. She did not go into detail but pointed to the dilemma of her double status: being a dedicated charen hoping to live a semi-segregated life apart from worldly disturbances to focus fully on tea-art practices and at the same time a businesswoman needing to involve herself in commercial activities to make a living. She sighed that it was a reality she had to accept.

Hence it was clear, right from the beginning of my apprenticeship at Julu, that the practice of tea art is a kind of self-cultivation. Just what this entails has never been clearly defined and seems to follow from Julu's unstructured program. Our classes often begin with a tasting. Students are either introduced to a particular tea, a series of tea, or ways of making them. The theme of a particular afternoon may emerge from tea we are tasting, the arrangement of the tea utensils, the larger aesthetic aspects of a ritual performance, or a discussion of tea practices. At one point, the master even let us arrange our own programs, e.g., designing tea sets, setting up tea spaces, inviting speakers, or reading texts. Sometimes the master prepares a certain agenda for discussion, but she mostly allows the class to flow with whatever focus emerges during class discussions or from students' questions.

Master Lee tends to shun any technique that makes steeping tea seem "mechanical". She avoids using measuring devices, for instance. We learn to estimate how much tea to put into a pot by sight, without depending on scales. If it happens that too much or too little is put into the teapot, we are taught to adjust by the subsequent procedures of letting the leaves steep for a shorter or longer period—sufficient to brew a good tasting tea. We are discouraged from using a timer or counting by numbers or breaths to measure the time the leaves steep; instead we are instructed to follow our "feeling of time", which is supposed to become more precise with long-term practice. Master Lee often stresses that she does not want us to fall into the habit of expecting a "normal" taste for any particular tea, which would call for following standardized procedures to make standardized tea for tasting, the way government-organized competitions require. She welcomes experimentation and personal expressiveness in the steeping process. In this regard, the practice of tea-making has room for much creativity and, like a true art, combines thought and technique in the steeping and tasting, and requires our full engagement.

Making a pot of tea is easy but making a pot of delicious tea is a different story. Steeping (paocha 泡茶) uses hot water to extract flavor from the tea leaves for drinking. The simplest way of making tea is to pour hot water into a cup with tea leaves in it. Many Taiwanese use this simple and convenient way to enjoy tea every day. But even with this simplest practice, there are factors to be particular about, for example, the quantity of tea leaves to use, the temperature of water, and the length of time to let the leaves soak before drinking. Going a step further to take the size and shape of the cup into account, a round one encourages the leaves to fully extend and release their flavor, whereas a multi-angled shape or too small a size may have negative effects in this 
regard. Having a lid helps keep the temperature steady but it may create a stuffy flavor if the tea is kept airtight for too long. Other concerns like the thickness of the cup, whether it is porcelain or pottery, the quality of the water (tap water, spring water), the source of heat ... can add up to a long list. In Julu and other tea clubs, too, such exacting considerations explain why tea drinking has developed into something the Taiwanese considers a genre of "art".

If the first step in learning Taiwan's tea art is to figure out the best combination of the many factors that go into brewing tea, Julu's more unstructured approach is helpful for learning the qualities that make certain elements fit well together. We pay particular attention to the flavor of water boiled in kettles made of different materials, such as pottery, iron, and silver. We even try to discriminate among tiny distinctions, for instance, the difference between water boiled in containers having dissimilar clay qualities, such as a sandy-versus a mud-based clay. Using the right teapot for brewing is another focus. In Taiwan, the stoneware-like Yixing clay teapots are the most popular. Compared to porcelain, which is thought to flatten out the taste of tea, Yixing clay is thought to yield a fuller flavor while also mellowing the astringent notes. There are quite a few kinds of Yixing clay, each having a different density, which are made into pots at diverse kiln temperatures. Teas steeped in pots made of different clays are thought to result in slightly different flavors. For example, vermilion-mud (zhuni 朱泥) with its glass-like quality is considered a good ware to boost aroma; while purple-sand (zisha 紫砂) clay improves the mouth feel (kougan 口感) of the tea.

All of these factors are further complicated by the fact that we drink a variety of teas and are particular about how each tea should be brewed. In Julu, we taste all sorts of teas, ranging from non-fermented green teas, partly fermented Woolong tea, fully fermented black tea, to post-fermented Puer. Woolong tea gets particular attention since it is the most popular tea in Taiwan, which has the distinction of being one of only three places in the world to produce it (the others being China's Guangdong and Fujian provinces).

The partly fermented Woolong demands not only sophisticated manufacturing procedures but also skillful steeping in order to present its unique flavor. For example, to properly bring out the unique taste of Taiwan's "high-mountain tea”, a medium-fermented Woolong with a light fragrance, we may use a silver kettle to boil the water, a vermilion-clay Yixing teapot, and use boiling water to steep the leaves. This selection of materials and techniques has its logic. Since high-mountain tea leaves come in a tightly rubbed ball shape, we apply actively boiling water to "force" the leaves to release their unique floral fragrance. As we also intend to let the temperature inside teapot cool down as the leaves steep to prevent the flavor from becoming bitter or astringent, we select a thin vermilion-clay pot with good heat conductivity, instead of a thick purple-sand pot that tends to keep the water temperature high and may overcook the tea. A silver kettle makes controlling the boiling process easier, compared to iron or pottery kettles, since we need to adjust the water temperature for each round of serving. The first round involves vigorously pouring boiling water into the teapot to loosen the leaves, then allowing them to steep for about one minute. With the leaves half-opened, we generally reduce the time and the water temperature in the second round so the tea does not become too strong; then we again heat up the water to increase the tea's strength in the third round, and finish with a fourth round.

Although serving tea appears to be a simple matter of steeping leaves in water, it requires the careful selection of utensils and consideration of how the tea should be served. The first lesson to be mastered in tea art is the proper steeping of a tea. 
Master Lee clearly intends her students learn all this by continuous practice, not through knowledge-based instruction. We are given little explanation regarding how certain things should be done. For one thing, she never explains, at least not verbally, why she forbids us to use scales and timers. She simply expects us to master the visual estimation or feeling for time by trial and error. For another, her answers to our questions are mostly short; she prefers to demonstrate how things should be done, for instance, showing us how to powerfully pour water into a teapot or how water boiled in kettle made of low-density clay is good for certain types of tea. She stresses that we should keep practicing until we have mastered and can perform every detail spontaneously, no matter which tea we are to serve. She wants us to learn the materiality of the teas and utensils by heart, so to speak, not simply as a form of intellectual knowledge. This is particularly clear when it comes to practicing for public tea gatherings. We are required to practice repeatedly. Master Lee drinks our tea and gives comments and suggestions, then leaves us to make adjustments until we figure out by ourselves how to make the tea right.

Master Lee's emphasis on internalization through continuous practice is intended most significantly to foster a certain aesthetic, rather than simply train us in the act of properly steeping tea. Master Lee is famous for her aesthetics in Taiwan's tea community, especially for organizing and performing at public tea gatherings. Ritual performance, individual tea utensil design and arrangements, as well as creativity are very much emphasized in her classes. Our weekly session is often conducted ritualistically, with a few classmates practicing the tea ritual using spatial settings and utensils of their own design. The Taiwanese-style tea ritual can be traced to that of China's Chaozhou area, which is called gongfucha (工夫茶), indicating its sophisticated steeping procedures and the time-consuming nature of the tasting process. Chaozhou's basic tea set includes a few small cups, a two-level clay tray (called a tea boat) to hold teapot and water, a small clay teapot, and a kettle for boiling the water. The host, who takes charge of the scalding tea, controls the rhythm of brewing and tasting, and often leads the conversation. The host boils water, uses the heating water to warm the teapot and cups, places tea leaves into the pot, pours in the hot water, distributes tea into individual cups, then invites the guests to enjoy the tea. This sequence might be repeated for a few rounds as conversation proceeds. Today this Chaozhou style of steeping and tasting tea remains quite popular in Taiwan; its ritualistic aspect provides an excellent occasion for interaction among family and friends, making it the most common communal ritual inside Taiwanese homes.

Julu's tea ritual is very much based on this Chinese legacy, but the material culture, aesthetics, and the style of movement associated with it have been enriched and elaborated to an exquisite level of refinement. Several items have been added, including a small piece of cloth for cleaning, a jar or bottle storing the tea leaves, a spoon to transport the leaves into the pot, a clay pitcher for distributing the tea among individual cups, and one or two small plants. Underneath the tea utensils, Master Lee often places one or two layers of cloth, wood, bamboo screen or wallpaper to provide contrast to the utensils and represent seasonal changes or mark the occasion of a tea event-a particular festival, for instance. To arrange all these in an artistic way requires the students' long-term observation and practice. Certain principles are clearly spelled out, such as arranging utensils to allow a smooth flow when serving tea, assembling utensils with similar functions into small groups (instead of scattering everything on the tea table), or selecting just one eye-catching object-an antique or a utensil with a significant design — to use in the set. Making the arrangement looked orderly and stylish also 
relies on certain implicit "rules" that are hard to spell out. We can only learn by observing how Mater Lee makes adjustments, replacing certain elements with others or re-arranging the order of the utensils.

The matter of understanding tea aesthetics is further complicated by the fact that Taiwan's tea-room setting, ritual process, and symbolism are still developing, in other words, Taiwanese tea art is the process of the "invention of tradition" of what Hobsbawm (1983) describes. The embrace of modern tea art in Taiwan is relatively recent, beginning only in the mid-1970s. Before the 1980s the emphasis was mainly on the skills of steeping tea; but by the late 1970s we began to see new efforts to enrich tea art's cultural aspects. Probably because Taiwanese faced fewer obstacles in continuing their Chinese legacy, Taiwan's tea culture community has enjoyed more freedom to create new forms of aesthetics, especially when it comes to experimenting with spatial arrangements, the designs of utensils, and the styles of public tea rituals. Traditional and contemporary approaches both also incorporate Japanese elements. We tend to see ambitious creativity among the different tea clubs, but no standard of movement, ritual process, or stable meaning system around these practices has developed. For example, opinions differ on just what constitutes an elegant body movement, a gesture that is “just right”—not so showy as to give the event “a commercial tone” (jiangqi 匠气) nor so conservative as to appear mechanical. Views differ as well as to whether water should be poured with power or gently into the teapot. No dominant masters have emerged to establish their own tea art sects that possess both distinctive forms of ritual and aesthetics and a well-developed philosophy. We find mainly small tea clubs or loosely organized tea-culture societies similar to Julu. As a result, Taiwan's tea art has remained characterized by its informal and less structured but flexible and creative nature. Unlike her Japanese counterpart, Taiwan's tea art community does not have a clear consensus allowing members to develop their own forms with a clear baseline. Japan's "way of tea" has gone beyond its well-structured tea ceremony, performed inside small tea rooms of certain standard designs and material elements; it has also explored the realm of spiritual expression since at least the 16th century. Taiwan is still in the process of experimenting with the material culture and aesthetics of tea. In this sense, tea culture in Taiwan is virtually an "art” under development, rather than a well-established cultural practice inherited from tradition.

This seems especially true since periodically new elements are added. A cup designed specifically for sniffing tea's fragrance was developed in the 1980s when high-mountain tea became popular. As the light sweet floral fragrance became the focus of tasting, a cone-shaped cup was developed to enable one to sniff the condensed fragrance attained through the drying process when the tea is transferred to the drinking cup. As this sniffing cup lines up side by side with the drinking cup, it also complicates the arrangement of the tea set and the tasting process.

The most significant creation is probably the so-called dry-style of steeping tea. The Chaozhou style two-level tea boat used to hold water is replaced by a normal plate that does not hold much water and thus demands greater care in pouring. This design is meant to avoid the feeling of messiness caused by excess water in the brewing process and reduces the unpleasant or inartistic aspects of the ritual. This new development has opened the door for a more creative assembling of utensils since the plate underneath the teapot can be replaced by a bowl, a piece of wood, stone, metal or many other possibilities. In recent years, Japanese antique tea wares and modern pottery have also been incorporated to enrich tea set presentations.

My entry into the Julu tea society took place at the peak of these modern developments, as tea gatherings 
of different natures were being organized by competing clubs. Nowadays, new utensils are being created by local and Japanese designers, stores once mainly selling Chinese antiques have turned to Japanese antique tea wares, and teas of all kinds are being imported into Taiwan, especially from China. This phenomenon has been dubbed “one hundred flowers blooming at the same time” (baihua qiming 百花齐鸣) by one of Taiwan's tea experts. Julu's aesthetics are also gradually transforming as Master Lee periodically invites her students to experiment with new elements, music, spatial designs, and scales of tea gatherings. Many of her students are professionals in interior design, architecture, and the arts, and their experiments are much welcomed. This has presented me with great challenges, since I have had to transform myself both in attitude and status from an observer to a real participant—even playing a part in Julu's construction of Taiwan's tea culture.

\section{Challenges}

\section{“That's Your Style"}

My first challenge came when Julu was invited to organize an important public tea gathering at the National Theater Concert Hall. Weeks before the event, we all prepared our tea sets and two kinds of tea, which had to be approved by Master Lee. The theme was "The Eve of the Lantern Festival," and I thought I should prepare utensils reflecting cheerfulness and the season, this being the first festival after the Chinese New Year. I chose a red lacquered box to hold the teapot, a small antique tin tea jar and a set of tin teacup stands carved with pine tree, bamboo, plum flower, and orchid. Since I did not have many utensils, I assembled what I considered the best pieces from my tiny collection. Master Lee quickly scanned my tea set, politely smiled at me, and said, “The tin tea jar and the teacup stand set are pretty but they are not your style”. Probably because I looked so confused by this, she advised me to go in the opposite direction, sticking with a plain and simple set, rather than the stylish sets most of my classmates had put together. Master Lee apparently had developed her own idea of who I was and wanted me to present it through my tea set.

The following week, I brought an unadorned teacup stand with an aged patina, which Master Lee immediately liked. She then taught me how to use a piece of paper to wrap tea, to replace my tin tea jar, and found an antique bowl for holding the teapot, instead of the showy red box. I then put a bamboo screen underneath my utensils and finished with a pot of bamboo I had grown. My tea set was ready.

Two weeks later as I was practicing tea steeping for the event, Master Lee came to my table again. She asked me which among my utensils best represented me? Her question again puzzled me; although I knew clearly how objects represent one's identity in anthropological terms, I had never thought I should seriously consider my social personhood and consciously represent it in a material manner. As Gell (1998) has taught us, selfhood is externalized and distributed in space through different material objects, and so assembling a tea set is in fact a form through which my "self" is exposed to the outside world (p. 21). As an anthropologist, I had been observing Julu's construction of taste and appropriation of things, but it never occurred to me that I, too, should or could play a role in the process I was studying. Since she had been working to construct a Julu art style, it was natural for Master Lee to associate her students with aesthetic styles; after all, Taiwan's tea culture is self-acclaimed "tea art". Throughout my four years of fieldwork in Julu, I had been struggling to find a material representation of my personhood—a male scholar (dushuren 读书人) who loves tea and anthropology. 


\section{“Mr. Yu, You Do Not Seem to Have Entered the World of Tea”}

The second challenge came when I gave a short presentation to my classmates after visiting Puer tea production areas in Yunnan, China. Besides introducing the places I had been to, I showed slides of how Puer is made nowadays in the famous region of Yiwu - the top area for tea production in Qing Dynasty that resumed production only in the early 1990s. I pointed out that after experiencing changing regimes and the great political tumult of the Great Leap Forward and the Culture Revolution, in addition to having not produced Puer tea for more than 50 years, this once most-famous Puer production region had actually lost its techniques and even basic knowledge about its tea. ${ }^{1}$ Today's local tea production meets only market standards rather than being based on a tradition. Local producers have adopted techniques brought in by merchants who combine manufacturing procedures and skills used for producing other teas, especially the partly fermented varieties. I concluded by questioning whether there was an "authentic manufacturing procedure" for Puer, as is claimed in all kinds of promotions. My questioning got my classmates' attention, but Master Lee apparently came to her own conclusions. After my talk, she approached me and said, "Mr. Yu, I find you are only interested in the phenomenon but not in tea”.

Being seen as unable to fully "enter the world of tea" has been a problem for me throughout my years of fieldwork. For one thing, I do not seem to have the sensibility needed for a good charen. I have good memories of tastes I have experienced but I am not good at sensing the delicate details of tea flavors and aromas. Often, I cannot distinguish between spring water and pure water from reverse osmosis, as my classmates do. We often take turns in expressing our experiences after tasting a tea, but I often find I have little to say. Master Lee once mentioned that sensibility declines gradually with aging as the number of taste buds reduce significantly after the age of 50. I hoped she was trying to comfort me since I was the only one over 50 in the class. Another issue is that I often do pay more attention to how a particular tea is being tasted and interpreted. As I focus on how my classmates describe their tasting results, more often than not I tend to quickly empty my cup without seriously tasting the tea. Also, I am inclined to be a "rational" taster who often tries hard, probably too hard, to discover objective principles or explanations in tea tasting. I find it difficult to comprehend descriptions or tasting categories that appear "mythical" or beyond my imagining ability. The problem is that these occasions actually occur rather often. While my classmates eagerly talk with Master Lee about finding the right match between cups and tea, describing what a "clean" taste is, or linking the "size" of a water molecule to a taste, instead of attempting at following their portrayals to sense what they are actually experiencing, I habitually search for rational explanations, from my knowledge of chemistry, physics, and symbolism too, and wonder to what extent their tastings are influenced by imagination and other cultural discourses.

My tea knowledge also appears to hinder my "direct tasting”, if there is such a thing. As I have gathered different theories and discourses regarding tea production, the aging process, markets, symbolic meanings, and consumption, these often appear first in my mind and potentially influence my tasting. Being an anthropologist interested in the recent theoretical and philosophical discussions about body subjectivity, I often find that

\footnotetext{
${ }^{1}$ A number of Taiwanese tea merchants visited Yiwu in 1993 for the first time after Yunnan opened its doors to Taiwan. According to one of the visitors, DENG Shi-hai, local officials could not find any producers from the older generation or tea experts from any of the old tea firms (1995). They located only one elderly shop assistant who could hardly describe what he had observed when Yiwu was still producing Puer tea.
} 
knowledge stored in my brain significantly interferes with my tasting when Master Lee asks us to let go of biases and "genuinely" taste the tea.

I consider myself a researcher of phenomena, not a tea expert. I have studied Puer tea as a socio-cultural and economic phenomenon, but I have only limited knowledge of the tea itself when compared to Puer experts who can appraise the authenticity of aged Puer tea, or know by heart the history of a particular tea firm. My job has been to demystify the stories and discourses surrounding Puer tea consumption and sort out what the Puer fad is all about (Yu, 2006). To a great extent, I stepped into Julu with a similar attitude-planning to study tea culture rather than becoming a tea expert, never mind a tea art practitioner. Probably because I often express myself with anthropological theories in mind, Master Lee sees me as "one who appears oriental-oriented but thinks Western”.

\section{“Mr. Yu Often Appears Having Something to Say But He Refrains From Doing So”}

Since I first stepped into Master Lee's classroom, I understood that I would be engaging elitist taste that Bourdieu (1984) has analyzed in detail. As mentioned earlier, Master Lee has become renowned for her aesthetics. Through public tea gatherings, publications, lectures, the tea school, and a small tea shop, Julu has been quite successful at bringing new trends into Taiwan's tea and art communities, and promotes itself as an institution dedicated to cultural affairs. It breaks with the stereotype of tea art as mainly an inheritance from the Taiwanese/Chinese cultural past, by incorporating both contemporary (e.g., modern dance, new utensils) and traditional (e.g., nanguan music) elements into its aesthetic constructions and this has established Julu as a kind of tea art performing group. In recent years, its tea gatherings and exhibitions have been upgraded from events taking place in small local settings to the stage at Huashan Creative Park, the National Palace Museum, the National Theater Concert Hall, and even China's National Center for the Performing Arts. Julu's tea art performances have become widely recognized as a form of high art.

Master Lee named Julu's tea shop as "Non Solo Tea" which clearly points to her ambition to not solely focus on tea but something far beyond it. Aesthetics is prominent in every aspect of Julu practice, from dress, gestures, manners, talking, material preferences, and spatial designs, to subjects of conversation. This thoroughly aestheticized approach marks Julu as a unique group in Taiwan. To help make our movements appear natural, Master Lee invites a professor of dance at a nearby arts university to train the Julu students how to move, the idea being that we will learn to sit, walk, and move properly and maintain a sense of balance. She constantly pushes us to design tea sets and tea spaces in styles of all sorts, whether sumptuous or unadorned, or fashionable and original. Her critical comments are taken seriously even by my interior designer classmates, making her a charismatic arts leader. Master Lee clearly has a strong idea of what she considers good taste, although its precise contents may shift over time. Her intention is to create a certain taste or lifestyle that will influence or add an aesthetic cultural element to Taiwanese society. In this regard, Julu's tea gatherings are artistic performances and at the same time they promote a taste and lifestyle while demonstrating how tea can be consumed artistically. All these, if adopted thoroughly, are thought to enrich or improve other aspects of one's life.

Master Lee's charisma encourages students to reproduce her taste and lifestyle, although learning the Julu taste does not come easy. We often face Master Lee's challenges and criticisms, especially when we come up 
with new designs for a tea set or performance space. Since the training is not geared to a clear learning arc, my classmates put a lot of effort into trying to figure out Master Lee's aesthetics - collecting tea wares, looking for objects that can be creatively used in their tea sets, and even transforming their outward appearance (hairstyle, habit of dress) and temperament to meet the Julu standard. "Fitting the requirement" (daowei 到位) in all respects, along with the implicit competition this engenders among the students, has proved a constant source of pressure for Julu members; the perpetual quest to meet the standard remains a significant dynamic within Julu.

Another dynamic is the great effort members make to keep Julu a close-knit community. Small tea gatherings, whether in Julu or members' spaces, always end with a moment of sharing. If participating in a tea gathering is, in the Turner's (1969) sense, experiencing a ritual process, these moments of sharing are the stage when communitas is created and emotional bonds are establishing or reified among members. Members also use communication software, especially cellphone apps, to share opinions, ideas, and feelings after each event. Other than demonstrating that Julu members are like family, this sharing is central to praising the benefits of these events, which bring tea culture into members' daily lives. Enjoying tea in a periodic, aestheticized, and ritualistic manner has become a way to structure one's daily life—some even use terms like "cultivation" and "guidelines" to describe their efforts to make this highly conscious form of tea consumption an important part of their lives.

These dynamics pose a great challenge to me. Being a social scientist I am all too familiar with the critiques, in sociological terms, on modern "taste" and "lifestyle". Julu is very much class-based, having strong middle-class ideologies and interests. On another front, "taste" often entails Bourdieu's (1984) concept of "distinction" and an important ongoing discussion in Julu is exactly how to keep the group unique through its rich aesthetic originality and style of living, and distinct from other groups or from society in general. My fellow classmates take pride in being Julu members. As a research fellow at Taiwan's elite research institute, I am expected to reconfirm the beauty and value of Julu's artistic style, as professors of arts and literature do. But I strives to avoid playing such a role; I tend to demur from making statements that might flatter Julu and refrain from pointing out that aesthetic taste is subject to socio-cultural dynamics rather than being something of universal value, to be discovered through the practice of tea art, which many Julu members believe to be the case. My awkward situation is probably best described by Master Lee’s public remark: "Mr. Yu often appears to have something to say but refrains from expressing it".

\section{Classmates}

I share many of the same doubts and challenges as my Julu classmates. We are all training under the same charismatic teacher and experience similar frustrations at the lack of a systematic learning process and clear aesthetic principles to follow. Under pressure to come up with designs that meet Julu's aesthetic standards, at times we must face ourselves and figure out a style concomitant with our individual social personhood and temperament, even though we may not have a clear sense of this, as in my case. We sometimes discuss our doubts and frustrations when not in Julu, but in turn we also re-confirm to each other, and to ourselves too, that “learning tea” (xuecha 学茶) is our common goal as we search for a meaningful life in this modern world. Most of our classmates really come "with their whole hearts"- eager to learn tea art not only as a hobby but as 
a way of life, allowing the consumption of tea in a ritualistic and aesthetic manner to become a major focus in their daily lives. This is best represented by expressions like, "I love tea and that's what keeps me going”. Such expressions, at times, let me realize what Foucault (1988) meant by using "technologies of the self" to portray those self-engendering programs that can help members of modern society to find a way to, in Chinese terms, anshen liming (安身立命), settle down and get on with one’s pursuits.

Nonetheless, being a social scientist often leads me to diverge from my classmates. I understand that perspectives matter, and my anthropological background allows, and perhaps forces, me to perceive our practices differently. Master Lee every so often tells us that "we need to learn from tea" or "there is so much that tea can teach us". These statements are simply accepted by my classmates, who tend to assume that there is genuine virtue, a spiritual and material aesthetics, hiding underneath our tea practices_and it is waiting to be discovered rather than created. This motivates them to learn tea (culture) by learning from tea, and to work hard hoping that one day they can realize the very essence of this practice. As an anthropologist trained in the concept of socio-cultural construction, I cannot agree with the idea that gives tea almost a sacred role. This disagreement to some degree constrains me from having the same motivation and enthusiasm for cultivating myself as a charen, unlike my dedicated classmates.

The challenges I face in Julu add up to a field situation I have never faced before. I have pursued the method of "participant experience" (Laughlin, 1994; Jackson, 1983; Hsu, 1999), hoping my experiential involvement in the field would bring about in-depth comprehension that the mere observation cannot achieve. However, despite my past success with this experiential approach, which allowed me to establish a "contact zone” (shared communicative space) (Hastrup, 1997) with my research subjects in projects that looked at Buddhist meditation (Yu, 1998, 2003a) and the consumption of hot and cold foods (Yu, 2003b), I have found it difficult to share a comprehension of the world of tea that my teacher, and to some degree my classmates, are committed to. I understand clearly that I often pay attention to different things even when we are tasting the same tea at the same time. My best efforts to pay more attention and integrate myself into Julu have still not allowed me to totally immerse myself in, or go native, so to speak, in the world of tea.

Further, this has been the only field experience in which I have been eagerly hoping I will have a chance to share my anthropological perspective with my research subjects. I hope to persuade them that what they need to do is not "discover" the genuine beauty or virtue in tea, but to proceed with inventing a Taiwanese tea culture with both the traditional and modern materials available to them. Ironically, mingled with my intention to provide my own professional expertise is my inclination to avoid making open comments about Julu's development, since I am expected to express appreciations rather than make suggestions for change. Since my social personhood is being constantly tested, I keep myself low-key at all times.

\section{Moments of Realization}

A turning point came when my wife decided to join Julu. Since our class had gone well beyond the beginners' stage when she joined, I naturally helped coach her in Julu's style of tasting, steeping, and ritual. This informal teaching was much less structured than what I had received in Julu. It took place in our everyday tea sharing, when we took turns steeping tea for ourselves or for guests, and when we practiced for special Julu tea gatherings. 
As I was demonstrating for my wife how we did certain things in certain ways, correcting what appeared not appropriate, or explaining what was a good tea and how to bring out its characteristic flavor, I began to realize how much the tea culture had become internalized in my body and mind without my awareness. I found I had become quite conscious of, and sometimes even felt irritated at, gestures that were not "appropriate”. But I had trouble explaining to my wife why certain bodily movements appeared rough or inelegant, and why moving too fast or too proficiently gave the impression of a commercial professional style, while moving too slowly might look unnatural or artificial. What I could do was demonstrate for my wife the way I had been taught, which now seemed quite natural to me. Similarly, I could not explain to my wife how certain sounds, like that of water being poured into a teapot, could give an impression of impatience and hurry, while others indicated power, a positive factor in making a good pot of tea. There were unspoken rules whose nature was tricky to describe. For example, there is no way to explain how one's steeping tea reveals his/her attitude in conducting a tea ritual. I did know that a right attitude came from long-term dedicated practice, and despite every step being carried out, an unfocused manner of steeping tea often resulted in an experience of lesser quality. When correcting my wife's gestures and movements, I began to realize how much tea art had become a part of my habitus. I could not stand watching water splash out of the teapot as she poured without telling her she needed to be more focused. Nor could I see her handle tea utensils with her little finger up (a mistake I often made, too), without reminding my wife that it looked coquettish. Playing the role of instructor, I was able to observe my own habits of conducting the tea ritual in the mirror image of my wife. From the perspective of an observer I became aware that unexpectedly certain actions looked unpleasant—for instance, when some movement appeared to cause two utensils to collide despite the fact that there seemed no chance of that from the perspective of the one who was steeping tea. I came to appreciate why Master Lee often said that our ways of conducting the tea ritual revealed our personalities. As a spectator watching my wife making tea, I began to read the ritual, too.

I also tried hard to teach my wife tea tasting. Although I am not a talented taster, I do understand that the "practiced mouth and nose" were key to enjoying tea. Luckily my wife seems to have a much better tasting sensibility than mine, though we often had trouble describing what we were experiencing. I often used tasting categories I learned from Julu and even though I now took many of these categories for granted, they were difficult to explain verbally: How to describe the kind of sweet taste (ni 淢) that, in tea, is a little bit “over” and gives a unpleasant feeling? The taste of ting (挺, “sticking out”) is another example. We took a long time to reach an understanding, after numerous tastings and discussions, of what ting represented as a category between us, similar to the process I had gone through with my Julu classmates. There were also many tasting experiences for which we found no terms. These occasions also made me realize that I had internalized many such tasting categories and had acquired the ability to identify them.

The critical point came as I was helping my wife design her own tea set. I understood that her tea set should reflect gender differences and imposing my style on her would be disastrous. As I considered what utensils were suitable and how to design a style that would represent her, I became aware that there were many unspoken rules, symbolic elements, and perceptual categories embedded within objects that express gendered characteristics in the Taiwanese context. These include numerous elements like shape, size, color, curves, thickness, smoothness, brightness, patina, and the infinite combinations of these elements. How to assemble the 
elements embodied in tea utensils into representations of formality, loveliness, delicacy, elegance, peacefulness, calmness, fashion, modernity, classicism, “quiet and poise,” or the fun in zhuo or zhuoqu (拙趣), an appreciation for things with no apparent skill or grace, and ultimately into a sense of Taiwanese femininity? Working out how to express my wife's personal style in accordance with Julu's standard became a formidable job if we intended to take all these potential constituents into consideration.

In the course of assembling a suitable tea set from our limited collection of utensils, I again realized how much I had learned and how much I had internalized. I consciously learned some of the categories under Master Lee's instruction, but to a greater degree, many of Julu's aesthetic elements became a part of me outside my awareness. In Bourdieu's (1977) characterization, my learning of these perceptual categories (in tasting and judging aesthetics) and body techniques (in conducting tea rituals and maintaining bodily balance) took place "from practice to practice" (p. 87), occurring as we took turns steeping tea for our classmates and discussing tastings in the classroom. Julu's unstructured, though not disorganized, program created a cultural environment, and through long-term interaction with Julu members, tea, objects, spaces, and tea gatherings, I became a Julu tea practitioner. This had happened despite the fact that I had hesitated to intentionally design my own style and had been reluctant to relax my social personhood as a researcher to engage fully with Julu's practices and ideologies. No matter whether I agreed with Julu's style or not, I had nonetheless learned to base my perceptions in this "everyday aesthetics" or the categories and dispositions (Bourdieu again) I acquired from Julu. It has been like enculturation, a concept anthropologists use to depict the process of cultural learning by growing up in a cultural environment, only I had learned as a fully adult member and learned in a context known among anthropologists as "fieldwork."

\section{Reflections}

These moments of realization, if not enlightenment, allow me to reflect on a few things. Bodily cultivation has been an essential part of my learning experience. I entered as a researcher, intending to study Julu from a social scientist's standpoint, that is, to fully participate in its cultural environment but also to study it. My hesitation at developing my own style and reluctance to engage fully in all aspects of Julu kept me at a distance, and to some extent allowed me to remain an observer and an objective researcher whose perspective would not be influenced by the fieldwork situation. But my internalization of Julu's aesthetics took place nonetheless, through an unstructured program that employed bodily cultivation as its key component.

This reminds me of Confucian teachings that stress the embodiment of cultural concepts and values, and the nurturing of social personhood through bodily cultivation. In the Confucian classics, bodily cultivation often focuses on practicing seemingly trivial things - gestures, physical movements, and the regulation of sensuous pleasures-as a starting point. For example, in his teachings about Confucian principles for the very young (yangzheng yiguei 养正遗规), the Song dynasty scholar ZHU Xi (朱喜) made bodily practices a major focus, including ways of walking (holding back when accompanying elders), sitting (refraining from occupying too much space), dressing (tightly fastened hats, clothes, and shoes), and practicing calligraphy (making properly proportioned brushstrokes). Encouraging young people to renounce indulgence in sensuous enjoyment and giving advice on regulating one's senses have been key instructional principles since the time of Confucius and continued to be highlighted in various eras of Confucian resurgence. These rather tedious teachings, called 
lijiao 礼教 (teachings in etiquette), were designed to help students internalize Confucian concepts. If we disregard the social and political implications of body politic (Foucault 1979) and focus only on the aspect of Chinese bodily practices, it is possible to recognize how important this mode of bodily cultivation has been to the Confucian tradition, not to mention the Daoist and Buddhist traditions, which integrate religious ideals with body and mind cultivation. Based on this view of cultural learning, one's perception is not acquired in a ready-made, packaged fashion through a process often called enculturation by anthropologists, but is a quality that emerges and becomes more fully articulated and expansive through one's experiences and the processes of cultivation (Johnson, 2000). The body is not regarded as merely the source of individual sensations and universal desires which may be disruptive of the larger social enterprise of culture; when cultural ideals are incorporated in practices, those practices become key to the internalization or demonstration of the ideals.

Aesthetics is "something that cannot be taught but is learned", to use Master Lee's words. A teacher can only define certain principles and frame some boundaries, rather than spell out the detailed contents of what constitutes an appropriate art form. It is by learning Julu's aesthetics through long-term immersion and bodily practices that students gradually acquire the Julu perspective; in this regard Master Lee's teaching can be characterized as Confucian. However, it does lack the well-developed philosophy that Chinese classical thought and its Japanese counterpart possess. But this is a problem that not only Julu faces. Neither Master Lee, nor Taiwan's tea community at large, has developed a theory or a clear discourse that would link practicing the tea ritual and bodily discipline to spiritual cultivation, despite all efforts to elevate tea art to the spiritual realm, which has always been considered its ultimate goal. The correlation between practicing tea art and the cultivation of emotional poise and a moderate temperament is mostly taken for granted. It is often treated as a basic assumption that needs no elaboration. Hence, instead of developing a philosophy of the way of tea, the emphasis among members of Taiwan's tea community has consistently been its aesthetic/artistic aspect. This lack of a clear theory may also be reflected in the term most often chosen to refer to Taiwan's tea culture: cha $y i$ (茶艺, tea art) is the preferred term in Taiwan; few experts use the Japanese cha dao (茶道, the way of tea), although both terms can be found in Chinese tea classics.

The strong artistic emphasis over the 30-year development of Taiwan's tea culture has been important to the formation of a style of life with tea as a focus in many Taiwanese households. The development of tea art since the 1970s has brought a civilizing process into domestic tea tasting and consequently into daily lives, making consuming tea in a ritualistic manner a very popular practice, probably only second to the sharing of meals. The flourishing of the tea utensil market, with creations of artistic tea wares since the 1980s, and the craze for Yixing tea pots in early 1990s, as well as the popularity of tea art clubs and lectures all are manifestations of this trend. My close observation of Julu members also shows that this civilizing process provides strong impetus for aestheticizing their domestic lives, with members enthusiastically designing tea spaces at home and using tea sharing as a way to organize their home lives and social relationships. Many stress that observing a formal and aesthetically driven tea-time allows them to slow down and enjoy a focused and peaceful moment apart from the daily hustle and bustle. For those who had little exposure to the high arts before entering Julu, learning tea art has opened a window through which they can perceive and experience a way of life that would not have been accessible to them otherwise. No wonder some members use terms like "guidelines" or "focus" to describe the role tea art plays in their everyday life. By enthusiastically immersing 
themselves in a tea art environment that stresses practice instead of knowledge-based instruction, Julu members discover a lifestyle they very much appreciate.

As a social scientist equipped with radical views toward issues of taste and lifestyle, I find that my Julu experience provides a chance for me to rethink these social perspectives. Most sociological theories of taste and lifestyle are class or status based. No matter whether the issue is "homology" (a strong correlation between class stratification and lifestyles, e.g., Gans, 1974 and Bourdieu, 1984), "individualization” (a flexible relation characterized by freedom and self-realization, e.g., Beck, 1992, Giddens, 1991, \& Warde, 1997), or the “omnivore-univore" position (a relation that is flexible but reflects proportional difference between classes, e.g., Peterson, 1992), all base their arguments on a single concern — the relationship between cultural consumption and class-based stratification. The case of Julu and Taiwan's tea art provides rich information that would allow us to examine this concern, but this is an issue too complicated and deserves a separate paper. Nevertheless, here are a few brief points: Julu involves members of various classes (thus a simple homology argument won't work), who participate in a cultural program to explore the meanings in self-realization and at the same time to accumulate cultural capital (hence making the "individualization” position hard to apply). They are involved in creating a highbrow cultural form to be consumed by different classes and cannot in any way to be depicted as a dominant group (this challenges the omnivore-univore position). Thus, teasing out the sociological significance of Julu will take much more in-depth discussion.

Instead I would like to bring attention to something all of these three positions neglect-distinction, habitus, taste, and lifestyle, concepts that above three positions based, which are very much founded on a shared "sense-scape", a cultural world of sensory experiences in which bodily cultivation is a mode of cultural learning. Julu's case demonstrates that Taiwan's tea art emerged from long-term socio-cultural developments involving Taiwan's historical and cultural connection with mainland China, her colonial past, and a continued close cultural bond afterwards, then a separation from the Communist China from the late 1940s to the late 1980s, followed by renewed and intense interaction in recent years. For these most recent years especially, we may talk about the civilizing process, the invention of tradition, the culture industry, and globalization processes. Julu is a part of this historical development; its distinctive forms of aesthetics and its tea ritual should be examined in that historical context. This is to say, Julu's style of tasting tea, regulating bodily movements, tea set aesthetics, and spatial arrangements, are considered distinctive and deserving of appreciation because they are perceived, enjoyed, and at the same time judged by members of Taiwanese society who share the same "sense-scape". That my classmates and I were able to recognize the elegance in our teacher's demonstration, or were capable of trying to figure out Master Lee's tasting categories, was very much related to the fact that a sense-scape had been implanted in us through enculturation processes with bodily practices at their core. Although we had not actually performed anything like a tea ritual beforehand, our teacher's demonstration made sense to us, not because we had been taught other similar movements in a tea school, but because we had learned numerous other movements and their meanings in our lifetime, through which Master Lee's demonstration was comprehensible. By the same token, our ability to comprehend ting as a tea tasting category was because we had learned to identify the categories of sweet, astringent, bitter and numerous others, as we grew up in a Taiwanese environment. Through these we could imagine and construct what ting was like from a mouthful of tea Master Lee provided. There is no way to tell whether all of us 
constructed and tasted the same ting from the same tea, but our continuous tasting and discussion help us to establish and internalize this new category into our sense-scape. In other words, we, as members of Taiwan's society, may add new elements to this sense-scape but these new elements, no matter whether they are tasting categories, movements, meanings of elegance, or ritual styles, or no matter they derive from tradition or from global exchanges, have to be based and constructed in this shared sense-scape, otherwise it would take great efforts in promotion or education for them to be accepted. That sense-scape serves as an interface allowing a dialectic relationship between our bodily practices (of tasting) and the world (tea in this case), or between tastes and members of different classes (if we want to argue for the correlation between class and lifestyle). The shared sense-scape can be said to form the very basis of culture, upon which various cultural and social forms, like Julu's tea art and its taste and values, can be built. Studies of taste and lifestyle should pay more attention to how people are using their sense-scape to "make feel and also to make oneself feel" (Hennion, 2007, p. 101) as they construct ideal worlds for themselves.

\section{Conclusion}

This paper attempts to document the long-term process of bodily and mindful cultivation for Taiwan's tea art practitioners from an anthropological, participant-observation, and self-reflective point of view. By relating my own and my classmates' learning experiences, I argue that the cultivation process is possible because we practice in the same sense-scape allowing our learning to transcend class and status boundaries.

In her book, The Tea Ceremony and Women's Empowerment in Modern Japan (2004), Etsuko Kato considers the tea ceremony in Japan as a form of bodily discipline. Drawing inspiration from Foucault, she stresses that behind the long-term process of learning the Japanese tea ceremony through intense exercises is the goal of “controlling one’s body movements so as to control one's mind” (p. 25). Although one can only master ceremonial body movements through corporeal memory that requires intense concentration and much repetition, the aim is not only to acquire the ability to conduct the performance at ease but to achieve tranquility and insightfulness through that intense bodily discipline. As Japanese tea masters and students practice intensively in their search for the way of tea, their Taiwanese counterparts present a less structured and more improvisational tea art. Nonetheless, the effort required to pursue cha yi still demonstrates how both bodily sensations and cultural concepts are cultivated and internalized within a shared sense-scape through bodily practices.

\section{References}

Beck, U. (1992). Risk society: Toward a new modernity. (M. Ritter, Trans.). London: Sage.

Bourdieu, P. (1977). Outline of a theory of practice. Cambridge: Cambridge University Press.

Bourdieu, P. (1984). Distinction: A social critique of the judgment of taste. (R. Nice, Trans.). Cambridge, MA: Harvard University Press.

Deng, S. (1995). Puer tea (in Chinese). Taipei: Fuzhong Tiandi Zazhishe.

Foucault, M. (1979). Discipline and punishment: The birth of a prison. New York: Vintage.

Foucault, M. (1988). Technologies of the self: A seminar with Michel Foucault. H. Gutman, \& P. H. Hutton, (Eds.). Amherst: The University of Massachusetts Press.

Gans, H. J. (1974). Popular culture and high culture: An analysis and evaluation of taste. New York: Basic Books.

Gell, A. (1998). Art and agency: An anthropological theory. Oxford: Clarendon Press.

Giddens, A. (1991). Modernity and self-identity: Self and society in the Late Modern Age. Cambridge: Polity. 
Hastrup, K. (1997). The dynamics of anthropological theory. Cultural Dynamics, 9(3), 351-371.

Hennion, A. (2007). Those things that hold us together: Taste and sociology. Cultural Sociology, 1(1), 97-114.

Hobsbawm, E. (1983). Introduction: Inventing traditions. In E. Hobsbawm, \& T. Ranger (Eds), The invention of tradition (pp. 1-14). Cambridge: Cambridge University Press.

Hsu, E. (1999). The transmission of Chinese medicine. Cambridge: Cambridge University Press.

Jackson, M. (1983). Knowledge of the body. Man, 18, 327-345.

Johnson, D. H. (2000). Body practices and consciousness: A neglected link. Anthropology of Consciousness, 11(3-4), 40-53.

Kato, E. (2004). The tea ceremony and women's empowerment in Modern Japan: Bodies re-presenting the past. London: Routledge Curzon.

Laughlin, C. D. (1994). Psychic energy and transpersonal experience: A biogenetic structural account of the Tibetan Dumo Yoga Practice. In D. E. Young, \& J.-G. Goulet (Eds.), Being changed: The anthropology of extraordinary experience (pp. 99-134). Ontario: Broadview Press.

Peterson, R. A. (1992). Understanding audience segmentation: From elite and mass to omnivore and univore. Poetics, 21(4), 243-258.

Turner, V. (1969). The ritual process: Structure and anti-structure. Chicago: Aldine Publishing

Warde, A. (1997). Consumption, food and taste. London: Sage.

Yu, S. D. (1998). Body cultivation and ritual performance: A case study of Ci-Xi (in Chinese). Bulletin of The Institute of Ethnology, 84, 1-35

Yu, S. D. (2003a). Meditation, daily lives and religious practice: An ethnographic approach based on Cixi case study (in Chinese). Bulletin of Department of Anthropology, 59, 116-151.

Yu, S. D. (2003b). The sensuous style of the body: Rethinking anthropological studies on hot and cold Medicine (in Chinese). Bulletin of Department of Anthropology, 1(1), 105-146.

Yu, S. D. (2006). Market, value, and the aged-flavor in Puer tea trade (in Chinese). Bulletin of Department of Anthropology, 65, 8-108. 